British Journal of Medicine \& Medical Research

11(7): 1-8, 2016, Article no.BJMMR.20520

ISSN: 2231-0614, NLM ID: 101570965

SCIENCEDOMAIN international

www.sciencedomain.org

\title{
Plasmatic Biochemical Variables Associated with Polymorphisms in the Endothelin-1 and Endothelin-1 Receptor a Genes in Hypertensive Patients: Pilot Study
}

\author{
Oscar Lassen ${ }^{1}$, Jimena Herrera ${ }^{2}$, Gladys Dotto ${ }^{3}$, Silvia Ojeda ${ }^{4}$, Alicia Garutti ${ }^{3}$ \\ Patricia Bertolotto ${ }^{4}$, Sandra Tabares ${ }^{2}$ and Adela Sembaj ${ }^{2 *}$
}

${ }^{1}$ Semiology Department UAMI 3, Center for Chagas and Hypertension Cordoba Hospital, Argentina. ${ }^{2}$ Biochemistry and Molecular Biology, School of Medicine, National University of Cordoba, Córdoba, Argentina.

${ }^{3}$ Central Laboratory, Cordoba Hospital, Argentina.

${ }^{4}$ School of Mathematics, Astronomy and Physics, National University of Cordoba, Córdoba, Argentina.

\section{Authors' contributions}

This work was carried out in collaboration between all authors. Authors OL and AS designed the study. Author AS wrote the protocol and the manuscript. Author OL selected and attended to patients. Authors JH, GD, AG and ST managed the experimental process. Authors SO and PB performed the statistical analysis. All authors read and approved the final manuscript.

Article Information

DOI: $10.9734 / B J M M R / 2016 / 20520$ Editor(s):

(1) Alex Xiucheng Fan, Department of Biochemistry and Molecular Biology, University of Florida, USA.

(2) Chan-Min Liu, School of Life Science, Xuzhou Normal University, Xuzhou City, China. Reviewers:

(1) Andrea Borghini, Institute of Clinical Physiology, CNR, Pisa, Italy. (2) Jaspinder Kaur, Punjab Institute of Medical Sciences, India. (3) Rajendra Nath, King George's Medical University, Lucknow (UP), India. (4) Volodymyr Chernyshenko, Palladin Institute of Biochemistry NAS of Ukraine, Ukraine. Complete Peer review History: http://sciencedomain.org/review-history/11732

Short Research Article

Received $30^{\text {th }}$ July 2015 Accepted $19^{\text {th }}$ September 2015 Published $7^{\text {th }}$ October 2015

\section{ABSTRACT}

Aims: Endothelin-1 (ET-1) is a potent vasoconstrictive peptide, and its activity is mediated by the type $A$ receptor $\left(E D N R_{A}\right)$. This action may play a significant role in the etiology of hypertension. There are different works that shows an association between certain polymorphisms of endothelin axis and clinical phenotype of hypertension. We describe the genetic variability $+138 / \mathrm{ex} 1$ 
insertion/deletion (I/D) adenosine (A) in the ET-1 gene and polymorphism thymidine/cytosine (T/C) His323His in the $E_{D N R}$ gene associated at the clinical variability in hypertensive patients.

Study Design: Observational, transversal and analytical study.

Place and Duration of Study: Hypertension Service at the Internal Medicine Department of Córdoba Hospital, and Biochemical and Molecular Biology Department in School of Medicine, National University of Cordoba, Argentine. Patients considered hypertensive between April 2009 and April 2010.

Methodology: Were assessed 136 patients serum lipid profiles, renal and hepatic functions and were taken Thoracic X-rays, electrocardiograms, and echocardiographs. DNA extracted from circulating leukocyte were used to analyze the polymorphisms of genes by PCR-RFLP.

Results: For the polymorphisms of Receptor A from Endothelin -1 studied the presence of cytosine homozygous genotype was less frequent in males $(P=.02)$. For both genders, the same genotype was associated to low plasma alkaline phosphatase activity and cholesterol levels. The presence of thymidine nucleotide allele correlated with plasma alkaline phosphatase activity and cholesterol levels. The Thymidine allele correlated with the degree of cardiovascular compromise $(r=0.54, P=.002)$. For the genetic variant in the ET-1 gene, the homozygous adenine deletion was associated to normal plasma levels of glutamate/pyruvate transaminase enzyme activity, uric acid concentration, cholesterol, and Low Density Lipoprotein in hypertensive subjects without clinical risk.

Conclusion: We observed a gender-specific protective effect for $E_{D N R_{A}}$ gene variations, the subjects that carried the TT genotype presented more aggressive symptomatology. These results show an association between plasmatic biochemical parameters, the clinical condition, and polymorphisms in the endothelin axis genes.

Keywords: Endothelin-1 gene; endothelin receptor a gene; genetic variation; hypertension.

\section{ABBREVIATIONS}

Endothelin-1: ET-1; type A receptor from Endotelin 1: EDNR $A_{A}$ Polymorphisms +138/exon1 insertion/deletion of adenosine in the ET-1 gene: +138/ex1 I/D A ET-1 gene polymorphism; thymidine/cytosine in the $E D N R_{A}$ gene: $(T / C)$ His323His EDNR $R_{A}$ gene; Polymerase chain reaction and restriction fragment analysis: PCR-RFLP; Genotype CC from polymorphisms T/C His323His EDNR gene: CC genotype; AlleleThymidine from T/C His323His EDNR $R_{A}$ gene: $T$ allele; Genotype deletion/deletion from +138/ex1 I/D A ET-1 gene: D/D genotype; LDL: Low-density lipoprotein; Hypertension: HT; Untranslated region: UTR; Messenger Ribonucleotide acid: mRNA; Insertion allele from +138/ex1 I/D A ET-1 gene: I allele; The Seventh Report of the Joint National Committee: JNC VII; electrocardiogram: ECG; 2-dimensional color Doppler transthoracic echocardiograph: EcoCG; thoracic X-rays: Thoracic Rx; single nucleotide polymorphisms: SNPs; glutamic/pyruvate transaminase: GPT; uric acid: UA; alkaline phosphatase: AP.

\section{INTRODUCTION}

Hypertension (HT) has a multifactorial pathogenesis that involves genetic and environmental factors that lead to increased arterial pressure. It is widely accepted that hereditary predisposition can induce the endothelial cell dysfunction and damage, thus contribute to HT development and its more frequent clinical manifestations [1].

Experimental and clinical evidence has shown that endothelin-1 (ET-1) plays an important role in vascular system pathophysiology due to its vasoconstrictory and hypertrophic actions. The interactions between ET- 1 and its type A receptor $\left(E_{D N R_{A}}\right)$ in vascular smooth muscle cells are the primary cause of ET-1-related vasoconstriction [2].

Several studies have shown that genetic variants in the endothelin system could influence $\mathrm{HT}$ and its clinical phenotypes [3-6]. One ET-1 gene polymorphism that has been studied is the insertion (I) or deletion (D) of an adenine (A) nucleotide at position 138 in exon 1, which corresponds to the 5' untranslated region (UTR) of the mRNA. This genetic variant has been shown to be associated to alterations in blood pressure values [7]. Spinarova et al. [8] have found a low relative risk of HT development in individuals with cardiac insufficiency and 
increased levels of plasma endothelin in heterozygote subjects with the I/D variant. Popowski et al. [9] reported that in human umbilical vein endothelial cells derived from homozygotes for the I allele, had significantly increased ET-1 protein expression levels, due to mRNA stability. Similarly, significantly higher plasma ET-1 concentrations were observed by Tanaka et al. [10] in Japanese patients with the I allele. Furthermore, the thymidine-to-cytosine (T/C) nucleotide change at position 69 in exon 6 of the $E D_{A}$ generates a polymorphism that has been shown to be a factor of prediction of the survival in patients with dilated cardiomyopathy [11].

The advance of medical science shows a participation of genetic background and its relations with the clinic evidence. The studies of polymorphisms demonstrate that could be considered as risks of factors for the development of cardiovascular pathologies, and would considered good tool with prognostic value in different entities [12]. Many of the studies were conducted in Caucasian European populations, however in Argentina there were few studies that showed the link between polymorphisms and clinical outcome. The Argentina populations consisting of European and native people. A study of Argentina community was necessary for observation of typical genetic variantions of this population. It also could offer potentially valuable screening tools for treating the hypertension and understandin of it's pathogenesis.

Based on the evidence, we proposed to know, whether polymorphisms are involved in the clinical symptomatology variety of the hypertensives. We analyzed the genetic frequencies the +138 /ex1 I/D A polymorphism in the ET-1 gene and the $\mathrm{T} / \mathrm{C}$ His323His polymorphism in the $\mathrm{EDNR}_{\mathrm{A}}$ gene associated to the values of biochemical variables in plasma in a cohort of patients defined as hypertensive.

\section{MATERIALS AND METHODS}

\subsection{Subjects}

A total of 136 patients ranged from 30 to 70 years of age, were not related to each other, regularly attended the Hypertension Service at the Internal Medicine Department of Córdoba Hospital considered hypertensive with similar disease-background, were recruited for a descriptive study. The hypertensive status was defined according to JNC VII [13]. A total of 59 individuals were considered as healthy controls, as they had normal systolic and diastolic arterial pressure (<140 - $90 \mathrm{~mm} \mathrm{Hg}$ ) and had never been treated with anti-hypertensive medication. All individuals completed a questionnaire about their family history of cardiovascular diseases and were subjected to a physical examination. The patients were treated according to the Helsinki declaration and gave signed informed consent prior to admission. This study was approved by the institution's Ethics Committee. Diabetic patients, pregnant women, patients with secondary hypertension, obese individuals, and individuals suffering from any episode acute at the time of the interview were excluded from the study. Once the patients were diagnosed, the blood samples were obtained, and the noninvasive tests were conducted, the patients were medicated and assisted with standard treatments.

A resting 12-lead electrocardiogram (ECG), a 2-dimensional color Doppler transthoracic echocardiograph (EcoCG) and thoracic X-rays $(\mathrm{Rx})$ were obtained for all subjects on the Cordoba Hospital. Independent observers scored the non-invasive test results.

Patients diagnosed as hypertensive $(\mathrm{HT})$ were classified as asymptomatic if, besides blood pressure values above 90 and $140 \mathrm{mmHg}$, they had normal a thoracic Rx, ECG, EcoCG, and clinical data. Patients were classified as symptomatic when the blood pressure values were above 90 and $140 \mathrm{mmHg}$ and at least one of the other tests was abnormal.

\subsection{Sample Collection and DNA Extraction}

Blood samples were collected from each subject at the Central Hospital Laboratory. hepatic and renal function, plasma lipid levels, and metabolic profiles were measured using the Dimension Analyzer (Siemens, Germany). A 1-mL aliquot of blood was used for DNA isolation according to conventional methods [14]. Polymerase chain reaction and restriction fragment analysis (PCRRFLP) was used to identify single nucleotide polymorphisms (SNPs) according to reference $[15,16]$.

\subsection{Polymorphisms Analysis}

The polymorphisms were determined by PCR amplification of $100 \mathrm{ng}$ DNA per patient. The amplification was performed in a Perkin Elmer Cetus Thermocycler (Waltham, MA, USA). All reactions were performed in duplicate, and 
positive and negative controls were used for both the PCR amplifications and the restriction digestion enzyme assays [14]. The analysis of the $\pm 138 \mathrm{EX} 1$ I /D A polymorphism in the ET-1 gene and $\mathrm{C} / \mathrm{T}$ His323His polymorphism in the $E_{D N R}$ gene were amplified by PCR with specific primers. The fragments were treated with the enzyme restriction for each polymorphisms $[15,16]$. Following digestion, the products were separated by electrophoresis on a $3 \%$ agarose gel or an $8 \%$ polyacrylamide gel and stained with ethidium bromide. When the results were ambiguous, the amplification products were sequenced to corroborate the specificity of the amplified fragment (ABI PRISM 310; Applied Biosystems,USA).

\subsection{Statistical Analysis}

Allelic and genotypic polymorphism frequencies were obtained from direct counts. The HardyWeinberg equilibrium was calculated. The differences in the clinical and biochemical variables between the groups were calculated with either the Chi-squared test or the Irwin-Fisher test. A $P$-value below 0.05 was considered statistically significant. The association between clinical variables and the polymorphic marker genotypes was analyzed with ANOVA and correlation analyses. The probability ratio and the confidence interval $(95 \%)$ were calculated in order to express the degree of linkage between the polymorphisms and clinical parameters. Statistical calculations were conducted with Infostat vs2007e software and the power of the study by Minitab 17 test.

\section{RESULTS}

\subsection{Population Characteristics}

Table 1 shows the demographic data and the main clinical characteristics of the patients included in the study.

\subsection{Genetic Polymorphism Analysis}

The genotypic frequencies of the $+138 /$ ex1 I/D A polymorphism in the ET-1 gene and the His323His polymorphism in the $E{ }^{2} R_{A}$ gene were analyzed. Their distributions were compared to those in the healthy control group, which comprised normotensive individuals without cardiac clinical manifestations. The distribution followed Hardy-Weinberg equilibrium. No statistically significant differences in the genotype distributions for either polymorphism were detected between the healthy control and hypertensive populations (Table 2). The frequencies of the TT genotype for the type A receptor polymorphism were $12.5 \%$ and $14 \%$ in the patients and healthy controls, respectively. The I/I genotype frequencies for the ET-1 polymorphism were $17 \%$ in the HT patients and $29 \%$ in the healthy controls. These frequencies are similar to those reported by other groups $[16,17]$. Due to the small number of homozygotes for each polymorphism, and with the objective of achieving a more rigorous statistical analysis, the less-frequent homozygotes were combined with the heterozygotes for all subsequent analyses.

The distribution of genotypic frequencies for the $\mathrm{C} / \mathrm{T}$ His323His $\mathrm{EDNR}_{\mathrm{A}}$ polymorphism analyzed by Pearson's Chi-squared test differed between the female and male populations, because the CC genotype was less frequent in males (16 (30\%) vs $34(43.8 \%) P=0.02)$. No statistically significant association was found between men carried the polymorphisms and the degree of cardiovascular disease.

The mean values and standard deviations of the biochemical parameters in the plasma from asymptomatic and symptomatic patients were assessed with the non-parametric Kruskal-Wallis test and were arranged according to genotype (Table 3). The mean values in the asymptomatic patients with the $D / I+I / I$ genotype were as follows: $23 \pm 6.5 \mathrm{mU} / \mathrm{mL}$ GPT, $3.86 \pm 1.02 \mathrm{mg} / \mathrm{dL}$ UA, $180 \mathrm{mg} / \mathrm{dL}$ cholesterol, and $97.24 \mathrm{mg} / \mathrm{dL}$ LDL, which corresponded to normal values. Therefore, the $\mathrm{D} / \mathrm{I}+\mathrm{I} / \mathrm{I}$ genotype in asymptomatic $\mathrm{HT}$ patients is associated with normal values of the aforementioned biochemical parameters. A similar profile was observed in asymptomatic HT patients with the CC genotype, which positively interacted with lower plasma values of AP $(198 \pm 55 \mathrm{mU} / \mathrm{mL})$ and cholesterol (172.3 $\pm 43.05 \mathrm{mg} / \mathrm{dL})$.

Finally, it was determined whether the allele frequencies $(\mathrm{C}$ or $\mathrm{T})$ of the His323His polymorphism in the $\mathrm{EDNR}_{\mathrm{A}}$ gene correlated with the degree of heart disease. For both genders, the $\mathrm{T}$ allele was statistically less frequent amongst asymptomatic HT patients (16 individuals, 26\%) compared to the 59 patients in second and third degree symptomatic. The latter group represented $40 \%$ of the sample size with the $\mathrm{T}$ allele. The presence of the $\mathrm{T}$ allele positively correlated $(r=0.54)$ with the degree of cardiovascular compromise $(P=.002)$ and the interval value $[-1,+1]$. The frequency of $\mathrm{T}$ allele carriers among the symptomatic patients with less cardiovascular compromise 
(asymptomatic and first-degree symptomatic) was similar to that observed in the healthy control group.

Table 1. Demographic data and clinical characteristics of patients

\begin{tabular}{|c|c|}
\hline $\mathbf{N}$ & 136 \\
\hline Age (years) & $56 \pm 14$ \\
\hline \multicolumn{2}{|l|}{ Gender } \\
\hline Female & $81(59.7 \%)$ \\
\hline Male & $55(40.3 \%)$ \\
\hline GPT † & $28.3 \pm 14$ \\
\hline $\mathrm{AP} \dagger$ & $217.9 \pm 23.1$ \\
\hline $\mathrm{TG} \dagger$ & $161 \pm 83$ \\
\hline Cholesterol † & $214 \pm 57$ \\
\hline HDL-chol † & $49 \pm 12$ \\
\hline LDL † & $124 \pm 36$ \\
\hline Uric Acid † & $4.49 \pm 1.35$ \\
\hline \multicolumn{2}{|l|}{$\mathbf{R x}$} \\
\hline - No alterations & $30(22 \%)$ \\
\hline - First-degree cardiomegaly & $42(31 \%)$ \\
\hline $\begin{array}{l}\text { - Second-degree } \\
\text { cardiomegaly }\end{array}$ & $57(42 \%)$ \\
\hline $\begin{array}{l}\text { - Third- and fourth-degree } \\
\text { cardiomegaly }\end{array}$ & $7(5 \%)$ \\
\hline \multicolumn{2}{|l|}{ ECG } \\
\hline - no alterations & $32(23.5 \%)$ \\
\hline - $\mathrm{CRBBB}+\mathrm{LAHB}+\mathrm{LVHB}$ & $47(34.4 \%)$ \\
\hline - + ischemia & $56(41.0 \%)$ \\
\hline $\begin{array}{l}\text { - AF or complete auricular } \\
\text { block }\end{array}$ & $1(0.7 \%)$ \\
\hline \multicolumn{2}{|l|}{ EcoCG } \\
\hline - No alterations & $81(59.8 \%)$ \\
\hline - EF $50 \%$ + chamber dilation & $28(20.5 \%)$ \\
\hline - EF below $40 \%$ & $9(6.6 \%)$ \\
\hline $\begin{array}{l}\text { - EF below } 30 \%+\text { chamber } \\
\text { dilation }\end{array}$ & $18(13.1 \%)$ \\
\hline
\end{tabular}

The numbers represent the numbers of individuals; percentages are in parentheses. $\dagger$ are expressed as the mean \pm the standard deviation. Normal Values: GPT (glutamic/pyruvate transaminase), $41 \mathrm{mUl} / \mathrm{ml}$; AP (alkaline phosphatase) < $270 \mathrm{UI} / \mathrm{L} ; \mathrm{TG}$ (triglycerides), < $150 \mathrm{mg} / \mathrm{dl}$; Cholesterol, < $200 \mathrm{mg} / \mathrm{dl}$; HDL-chol (high density lipoprotein-cholesterol), > $40 \mathrm{mg} / \mathrm{dl}$; $L D L$ (lowdensity lipoprotein) $<100 \mathrm{mg} / \mathrm{dl}$ and UA (uric acid), $<6$ $\mathrm{mg} / \mathrm{dL}$.; $C R B B B$, complete right bundle branch block;

$\angle A H B$, left auricular hemiblock; $L V H B$, left ventricular hemiblock; $A F$, auricular fibrillation; $E F$, ejection fraction

\subsection{Power of the Study}

On power calculations of the study was estimated to be 0.823 (82.3\%) for 136 hypertensions patients using +138/ex1 I/D A polymorphism for ET-1 gene as an example, with the probability of type 1 error being 0.05 .

\section{DISCUSSION}

Our first observation in this study was the rare occurrence of the CC genotype of the EDNR gene in male subjects $(P=.02)$. Furthermore, the CC genotype is associated with normal plasma AP activity and cholesterol levels in carriers who are clinically characterized at recruitment without injury in organ target. Although the sample is small and with the risk to committing type 1 errors. We can speculate that patients carrying the CC genotype would have a better prognosis for symptoms development because plasma cholesterol level is a risk factor of cardiovascular diseases. Additionally, it was shown that, for both genders, the $T$ allele of the same polymorphism positively correlated with more severe damage $(r=0.54, P=.002)$.

The $\mathrm{C} / \mathrm{T}$ His323His polymorphism, has been linked to decreased survival in subjects with dilated cardiomyopathy. Carriers of the $T$ allele have worse cumulative survival, compared to non-carriers [11]. Colombo et al. [17] reported that this polymorphism was linked to a significantly higher risk of cardiac failure. Furthermore, the His323His polymorphism is a prognostic predictor irrespective of age, clinical class according to the New York Heart Association, the left ventricular fraction, and the end-diastolic diameter [17]. Recently, Calabró et al. [16] described an association between the TT genotype, pulmonary resistance, and decreased cardiac index via cardiac catheterism in patients with pulmonary arterial hypertension. The mechanisms that would explain the potential effects of the TT genotype remain unknown because the substitution of thymidine ( $T$ ) for cytosine (C) does not alter the amino acid sequence of the receptor. How a synonymous codon could have such a profound effect on the phenotype has yet to be understood. A possible explanation could be that this polymorphism affects gene expression or post-translational modifications. Another potential explanation could be that the His323His variant causes a binding disequilibrium with another functional variant [11]. Despite this, Holzhauser L et al. [12] encourages the study of the polymorphisms of endothelin receptors. Because of it might lead to altered endothelin signaling and influence the response to endothelin receptor antagonist therapy in pulmonary arterial hypertension in light of pharmacogenetics.

HT pathogenesis is characterized by significant vascular resistance due to the biochemical and 
cellular modifications that lead to a dysfunctional endothelium, vasoconstriction, arterial wall thickening, and thrombosis. ET-1 plays an important vasoconstrictive role, and its plasma levels are elevated in several diseases [18-20]. Popowski et al. [9] found that homozygote I/I carriers expressed significantly higher levels of ET-1 (3.9-fold higher than the D/D variant). ET-1 increases the sympathetic activity induced by stress and arterial vasoconstriction. ET-1 activity damages the endothelium-dependent vasodilating function in hypertensive patients [2]. Therefore, functional ET-1 gene variants would contribute to the development of arterial pressure alterations [4]. Our study shows that hypertensive subjects who carry the A insertion, either as heterozygotes (I/D) or homozygotes (I/I), have normal plasma GPT, UA, cholesterol, and LDL levels. This suggests that a better metabolic predisposition compensates for HT. However, it has not been possible to establish a correlation between the degree of cardiovascular disease and $1 / /$ genotype carrier status for the $+138 /$ ex 1 l/D polymorphism. This is likely because several factors must act together in order to display a phenotype.

Table 2. Genotype distributions of the +138/ex1 ins/del A polymorphism in the ET-1 gene and the $\mathrm{C} / \mathrm{T}$ His $323 \mathrm{His}$ polymorphism in the EDNR $\mathrm{A}_{\mathrm{A}}$ gene in the patients and controls

\begin{tabular}{|c|c|c|c|}
\hline Genetic polymorphism & Healthy controls & Hypertensive patients & $P$-value \\
\hline$+138 / \mathrm{ex} 1 \mathrm{l} / \mathrm{D}$ A, ET-1 gene & n (\%) & n (\%) & \\
\hline $\mathrm{D} / \mathrm{D}$ & $10(17)$ & $25(18.3)$ & \\
\hline$D / I$ & $32(54)$ & $88(65)$ & \\
\hline $1 / 1$ & $17(29)$ & $23(17)$ & $P=.184$ \\
\hline \multicolumn{4}{|l|}{$\mathrm{C} / \mathrm{T}$ His323His, EDNR ${ }_{\mathrm{A}}$ gene } \\
\hline CC & $21(36)$ & $45(33.3)$ & \\
\hline $\begin{array}{l}\text { CT } \\
\text { TT }\end{array}$ & $30(50)$ & 74 (54.3) & \\
\hline 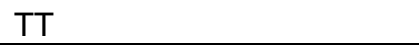 & $8(14)$ & $17(12.5)$ & $P=.180$ \\
\hline
\end{tabular}

Table 3. Polymorphism analysis for endothelin-1 and its type a receptor and symptomatic/ asymptomatic conditions

\begin{tabular}{|c|c|c|c|}
\hline Polymorphism genotypes & $\begin{array}{l}\text { Asymptomatic } \\
\text { Mean (SD) }\end{array}$ & $\begin{array}{l}\text { Symptomatic } \\
\text { Mean (SD) }\end{array}$ & P-value \\
\hline \multicolumn{4}{|l|}{ +138/ex1 I/D A, ET-1 gene } \\
\hline $\mathrm{D} / \mathrm{D}$ & $37.00(12.91)$ & $31.03(17.83)$ & .041 \\
\hline $\mathrm{D} / \mathrm{I}+\mathrm{l} / \mathrm{I}$ & $\begin{array}{l}23.00(6.54)^{*} \\
\text { UA }(\mathrm{mg} / \mathrm{dL})\end{array}$ & $31.85(34.63)$ & \\
\hline $\mathrm{D} / \mathrm{D}$ & $5.29(1.72)$ & $5.60(1.59)$ & .001 \\
\hline $\mathrm{D} / \mathrm{I}+\mathrm{I} / \mathrm{I}$ & $\begin{array}{l}3.86(1.02)^{*} \\
\text { Cholesterol (mg/dL) }\end{array}$ & $5.54(1.61)$ & \\
\hline $\mathrm{D} / \mathrm{D}$ & $206.0(50.63)$ & $224.18(59.96)$ & \\
\hline $\mathrm{D} / \mathrm{I}+\mathrm{I} / \mathrm{I}$ & $\begin{array}{l}180.0(52.07)^{*} \\
\mathrm{LDL}(\mathrm{mg} / \mathrm{dL})\end{array}$ & $223.27(54.57)$ & .032 \\
\hline $\mathrm{D} / \mathrm{D}$ & $130.29(37.65)$ & $124.64(31.21)$ & .013 \\
\hline $\begin{array}{l}\mathrm{D} / \mathrm{I}+\mathrm{I} / \mathrm{I} \\
\mathrm{C} / \mathrm{T} \text { His323His, } \mathrm{EDNR}_{\mathrm{A}} \text { gene }\end{array}$ & $\begin{array}{l}97.24(30.06)^{*} \\
\mathrm{AP}(\mathrm{mU} / \mathrm{L})\end{array}$ & $127.64(33.67)$ & \\
\hline CC & $198.50(55.43)^{*}$ & $264.51(88.26)$ & .032 \\
\hline $\mathrm{CT}+\mathrm{TT}$ & $\begin{array}{l}210.57(56.82) \\
\text { Cholesterol }(\mathrm{mg} / \mathrm{dL})\end{array}$ & $254.51(67.00)$ & \\
\hline CC & $172.30(43.05)^{*}$ & $241.02(64.84)$ & .003 \\
\hline $\mathrm{CT}+\mathrm{TT}$ & $198.50(56.45)$ & $205.28(40.16)$ & \\
\hline
\end{tabular}


Studies that have linked SNPs to functional pathological effects have not been repeated by other research groups. Similarly, the majority of studies that link polymorphisms to phenotypes and/or diseases are either cross-sectional studies or are limited by low patient availability. The latter is true for the current study, which makes such studies prone to possible sample selection bias. Validation of genotype-phenotype association studies requires replication of the results from a set of independent data and in a larger sample. Because, the low number of cases may causes a type 1 statistical error. It is necessary to be cautious before drawing conclusions. Even if the observations are statistically significant, we cannot prove that the polymorphisms in the ET-1 and type A receptor genes play direct roles in hypertensive symptomatology. For this purpose, the patient genotypes must be determined early and a follow-up study conducted to prove that the genotype plays a role in symptom expression and development $[3,4,11,17]$. Probably in this study the pathogenesis of HT is incompletely characterized, but it is likely to be multifactorial, involving the interaction between the genetic milieu and the environment of the individual.

\section{CONCLUSION}

It was observed that genotype distributions for both studied polymorphisms were the same for healthy control and hypertensive populations. Besides, the CC genotype from EDNR polymorphism was less frequent in males. In asymptomatic HT patients, the CC genotype was associated with normal plasma values of AP and cholesterol. Asymptomatic hypertensives patients with the $D / I+I / I$ genotype from polymorphism from ET-1 gene, had normal values of GPT activity and plasmatic concentrations of UA, cholesterol and LDL Although our results do not explain how the polymorphisms could directly affect cardiovascular disease pathogenesis and complications, it does not mean that a certain genetic background could play a role in exacerbating HT symptomatology in patients. We propose that, to follow the study to increase the sample size and the inclusion of a group of patients absence of $\mathrm{HT}$, but with similar conditions at the image studies examinations as disease control group. The challenge now is to determine how genetic variation influences the response to these stressors.

\section{CONSENT}

All authors declare that written informed consent was obtained from the patient for publication.

\section{ETHICAL APPROVAL}

All authors hereby declare that all experiments have been examined and approved by the appropriate ethics committee and have therefore been performed in accordance with the ethical standards laid down in the 1964 Declaration of Helsinki.

\section{ACKNOWLEDGEMENT}

The authors would like to thank all of the patients that participated in the present study. This work was supported by Science and Technology Secretary of the National University of Cordoba, Argentine (SECyT-UNC) and with personal funds.

\section{COMPETING INTERESTS}

Authors have declared that no competing interests exist.

\section{REFERENCES}

1. Kunes J, Zicha J. The interaction of genetic and environmental factors in the etiology of hypertension. Physiol Res. 2009;58(Suppl 2):S33-41.

2. Haynes WG, Strachan FE, Webb DJ. Endothelin ETA and ETB receptors cause vasoconstriction of human resistance and capacitance vessels in vivo. Circulation. 1995;92:357-63.

3. Asai T, Ohkubo T, Katsuya T, Higaki J, Fu $\mathrm{Y}$, Fukuda $\mathrm{M}$, et al. Endothelin-1 gene variant associates with blood pressure in obese Japanese subjects: The Ohasama Study. Hypertension. 2001;38:1321-4.

4. Dong $\mathrm{Y}$, Wang $\mathrm{X}$, Zhu $\mathrm{H}$, Treiber $\mathrm{FA}$, Snieder $H$. Endothelin-1 gene and progression of blood pressure and left ventricular mass: Longitudinal findings in youth. Hypertension. 2004;44:884-90.

5. Funalot B, Courbon D, Brousseau T, Poirier O, Berr C, Cambien F, et al. EVA Study. Genes encoding endothelinconverting enzyme-1 and endothelin-1 interact to influence blood pressure in 
women: The EVA study. J Hypertens. 2004;22:739-43.

6. Nicaud V, Poirier O, Behague I, Herrmann SM, Mallet C, Troesch A, et al. Polymorphisms of the endothelin-A and $B$ receptor genes in relation to blood pressure and myocardial infarction: The Etude Cas-Temoins sur I'Infarctus du Myocarde (ECTIM) study. Am J Hypertens. 1999;12:304-10.

7. Brown MJ, Sharma $P$, Stevens PA. Association between diastolic blood pressure and variants of the endothelin-1 and endothelin-2 genes. J Cardiovasc Pharmacol. 2000;35(Suppl 2):S41-43.

8. Spinarová L, Spinar J, Vasků A, PávkováGoldbergová M, Ludka O, Tomandl J, et al. Genetics of humoral and cytokine activation in heart failure and its importance for risk stratification of patients. Exp Mol Pathol. 2008;84:251-5.

9. Popowski K, Sperker B, Kroemer HK, John $\mathrm{U}$, Laule $\mathrm{M}$, Stangl $\mathrm{K}$, et al. Functional significance of a hereditary adenine insertion variant in the 5'-UTR of the endothelin-1 gene. Pharmacogenetics 2003;13:445-51.

10. Tanaka C, Kamide K, Takiuchi S, Kawano Y, Miyata T. Evaluation of the Lys198Asn and -134delA genetic polymorphisms of the endothelin-1 gene. Hypertens Res. 2004;27:367-71.

11. Herrmann S, Schmidt-Petersen K, Pfeifer J, Perrot A, Bit-Avragim N, Eichhorn C, et al. A polymorphism in the endothelin-A receptor gene predicts survival in patients with idiopathic dilated cardiomyopathy. Eur Heart J. 2001;22:1948-53.

12. Holzhauser L, Zolty, R. Endothelin receptor polymorphisms in the cardiovascular system: Potential implications for therapy and screening. Heart Fail Rev. 2014;19: 743-58.

13. National High Blood Pressure Education Program. The seventh report of the Joint National Committee on Prevention,
Detection, Evaluation, and Treatment of High Blood Pressure. Bethesda (MD): National Heart, Lung, and Blood Institute (US), Blood Pressure and Cardiovascular Risk; 2004 Aug.

14. Sambroock J, Russell DW. Molecular cloning: A laboratory manual. Cold Spring Harbor Laboratory Press, Cold Spring Harbor, Third Edition. New York; 2001.

15. Diefenbach K, Arjomand Nahad F, Meisel C, Fietze I, Cascorbi I, Stangl K, et al. Identification of twelve polymorphisms in the endothelin-1 gene by use of fluorescently labeled oligonucleotides and PCR with restriction fragment polymorphism analysis. Clin Chem 2004; 50:448-51.

16. Calabrò $P$, Limongelli $G$, Maddaloni $V$, Vizza CD, D'Alto M, D'Alessandro R, et al. Analysis of endothelin-1 and endothelin-1 receptor A gene polymorphisms in patients with pulmonary arterial hypertension. Intern Emerg Med. 2012;7:425-30.

17. Colombo G, Ciofini E, Paradossi U, Bevilacqua S, Biagini A. ET-1 Lys198Asn and ET (A) receptor $\mathrm{H} 323 \mathrm{H}$ polymorphisms in heart failure. A case-control study. Cardiology. 2006;105:246-52.

18. Salomone OA, Caeiro TF, Madoery RJ, Amuchástegui $M$, Omelinauk $M$, Juri $D$, et al. High plasma immunoreactive endothelin levels in patients with Chagas' cardiomyopathy. Am J Cardiol 2001;87: 1217-20.

19. Charron P, Tesson F, Poirier O, Nicaud V, Peuchmaurd M, Tiret $L$, et al. Identification of a genetic risk for idiopathic dilated cardiomyopathy. Involvement of a polymorphism in the endothelin receptor type A gene. CARDIGENE group. Eur Heart J. 1999;20:1587-91.

20. Matsa LS, Sagurthi SR, Ananthapur V, Nalla S, Nallari P. Endothelin 1 gene as a modifier in dilated cardiomyopathy. Gene. 2014;548:256-62.

(C) 2016 Lassen et al.; This is an Open Access article distributed under the terms of the Creative Commons Attribution License (http://creativecommons.org/licenses/by/4.0), which permits unrestricted use, distribution, and reproduction in any medium, provided the original work is properly cited.

Peer-review history:

The peer review history for this paper can be accessed here: http://sciencedomain.org/review-history/11732 